REMLATE DE MLALIE

Campinas-SP, v.39, n.2, pp. 684-702, jul./dez. 2019

\title{
Pela boca do pai? \\ TAMARA KAMENSZAIN E AS LÍNGUAS DO JUDAÍSMO
}

\section{THROUgh THE MOUTH OF THE FATHER? TAMARA KAMENSZAIN AND THE LANGUAGES OF JUDAISM}

\author{
Adriana Kanzepolsky
}

\begin{abstract}
Resumo: Este artigo investiga, na poesia de Tamara Kamenszain, o lugar ocupado pelo "judaico", concebido como uma condição que se herda do pai e que se transmite, inclusive a contragosto. Pensamos que essa condição se traduz nos poemas na recorrência de uma série de imagens/conceitos, entre os quais se destaca o significante gueto, e, com isso, a condição judaica entendida como narrativa que recupera um passado, uma genealogia, e que se abre para uma pergunta da ordem do procedimento: aquela que interroga acerca do poema como espaço propício para narrar a própria vida e, inclusive, como espaço favorável ou não à inscrição da intimidade.

Palavras-chave: pai, condição judaica, narrativa.
\end{abstract}

Abstract: This paper explores the place given to Jewish nature - which is conceived as a condition inherited from the father and passed on, even reluctantly, to others - in the poetry of Tamara Kamenszain. We hold that this condition is expressed in the poems by the recurrence of a series of images/concepts, among which the signifier ghetto stands out, and with it, the Jewish condition - understood as a narration that recovers a past, a genealogy - leads to a question comprising the procedure: the question that examines poems as appropriate places to narrate one's own life and even as favorable places (or not) to inscribe the intimate.

Keywords: Father, Jewish Condition, Narration.

1 Faculdade de Filosofia, Letras e Ciências Sociais, Departamento de Letras Modernas, Universidade de São Paulo (USP): <adrianak@usp.br>. 
"Del judaísmo no se puede emigrar, entre otras cosas porque la emigración en buena medida lo constituye, hace a su tradición, hace su tradición" (Martín Kohan, "La emigración en ciernes")

"Es un secreto que sólo una hija y un padre comparten como encuentro amoroso de lenguas intraducibles" (Tamara Kamenszain, La boca del testimonio)

Em “La musa freudiana”, a introdução de María Moreno (2014) para El libro de los divanes, o último livro de poemas de Tamara Kamenszain - no qual, para dizer muito rapidamente, a poeta examina a relação entre sua poesia e suas diversas análises e analistas, ou entre sua poesia e o relato da própria vida que é fiado/desfiado nos diversos divãs -, a autora do prólogo imagina/recorda uma cena em que, sendo ambas muito jovens, Kamenszain demora para começar uma entrevista que lhe havia concedido por ocasião da publicação de De este lado del Mediterráneo (1973), seu primeiro livro, porque está ocupada pendurando um antigo relógio de corda na parede. Moreno (2014, p. 7) conta que, "sorrindo" e "meio que desculpando-se", a poeta iniciante diz a ela que o relógio "lhe foi dado pelo pai". A frase com que María Moreno conclui essa "recordação" é a seguinte: "Penso que Tobías Kamenszain toma o tempo de Tamara, o tempo de escrever os livros que virão" (p. 7).

Entre irônica e afetuosa, a conclusão à qual Moreno chega naquela oportunidade ou à qual chega agora, depois de vários livros de poemas em que a figura do pai da poeta se mostra inevitável, é certeira. Presente já naquele livro de 1973, no qual lhe é dedicada uma das "prosas poéticas", Tobías Kamenszain reaparece nas obras seguintes dessa escritora e é o nome em torno do qual, desde a dedicatória, articula-se El ghetto, de 2003, livro em que o luto pelo pai se constrói como uma metonímia das perdas históricas do judaísmo.

2 Trata-se de um texto de pouco mais de uma página, no qual ela situa o pai no centro de uma linhagem em que figuram sua própria mãe, que nessa época completava 80 anos, e as filhas que "crecen como los árboles de todos los países" (KAMENSZAIN, 2012, p. 91). Já desde esse texto de sua fase inicial, a representação da figura paterna é associada a práticas do judaísmo e dita em termos que remetem ao imaginário judaico. Fala-se da Argentina como de uma terra em que "también hay leche y miel" e, para delinear o universo familiar, Kamenszain recorre à imagem da árvore, que persistirá ao longo de sua obra poética. Enquanto aqui alude ao pai como raiz dessa árvore, na década de 2000 a árvore se converterá em um suporte para inscrever as sucessivas mortes familiares. Todas as traduções de citações neste artigo são nossas.

Remate de Males, Campinas-SP, v.39, n.2, pp. 684-702, jul./dez. 2019 - 685 
Não pretendo me deter agora nas diferentes modulações que essa figura adquire nos poemas da escritora, mas sim voltar a ela para afirmar que, na poesia de Kamenszain, o judaísmo é, sobretudo, um assunto paterno. ${ }^{3}$ Isto é, um assunto vinculado, em primeiro lugar, ao luto pelo pai e, em um sentido mais amplo, à herança, à pergunta sobre o que é aquilo de que o sujeito lírico se apropria na posição de parente, do que é que se apropria com a morte do pai, o que recebe e o que seleciona; ${ }^{4}$ mas também vinculado à pergunta acerca do que é isso que "pesa como herencia", e, no entanto, se transmite, assim como podemos ler em "Bar Mitzvá" (2003), poema sobre o qual vou me deter mais adiante.

A identificação entre esses dois termos - pai e judaísmo - é tão profunda que, morto o pai, o aramaico da reza na boca de outros homens converte-se em um idioma estrangeiro. Na terceira estrofe de "Kaddish", o poema central de $E l$ ghetto, no qual insistentemente se pergunta “Qué es un padre?”, ela escreve: “Qué es un padre?/ Diez hombres lo invocan el martes/ en un espacio sin él/ su idioma/ resuena extranjero" (KAMENSZAIN, 2003, p. 33). Com a morte do pai desaparece também a familiaridade em relação ao judaísmo, ou a uma certa forma de relacionar-se com ele, pelo menos do modo como o pai o fazia. ${ }^{5}$ Nesse sentido, quando me refiro ao judaísmo como uma condição que nesses poemas está inextricavelmente ligada ao luto, penso nesse conceito - o de luto (duelo, em espanhol) - vinculado à dor pela perda, mas também o remeto a outra zona de suas etimologias, que o relaciona com a ideia de "batalha", "desafio" e "combate entre duas pessoas". ${ }^{6}$ Batalha, desafio e combate entre dois, entendidos como luta com a dor para voltar a se conectar à vida,

\footnotetext{
3 Analisei o lugar que cabe a essa figura na poesia de Kamenszain em: "Aquí llegamos, aquí no veníamos” (KANZEPOLSKY, 2010), acerca de El ghetto de Tamara Kamenszain. e em "Reverberações do luto ou acerca da morte em família (2014).

4 Parafraseio aqui uma afirmação de Oscar Terán (2003, p. 6) ao escrever: "[h]erdar significa recuperar, mas também selecionar".

5 A esse respeito talvez caiba citar uma reflexão de Maria Rita Kehl (2014, p. 18) em "Melancolia e criação", introdução à edição brasileira de "Luto e melancolía" de Freud, quando assinala: "A perda de um ser amado não é apenas perda do objeto, é também a perda do lugar que o sobrevivente ocupava junto ao morto".

6 Em “Dolus-Duellum", o primeiro capítulo de Los tiempos del duelo, Adriana Bauab (2001, p. 13) escreve: "O termo duelo em espanhol é uma palavra homônima: recaem sobre ela dois significados. Etimologicamente, provém de dois vocábulos latinos: - Dolus, do latim tardio, que significa dor, sofrimento ou aflição. Demonstrações que se faz para manifestar o sentimento que se tem pela morte de alguém./ - Duellum, variante fonética arcaica de bellum, que significa batalha, desafio, combate entre dois".
} 
mas também e simultaneamente à batalha por reapropriar-se da herança a partir de um lugar diferente.

A esse respeito, creio que vale a pena recuperar algumas reflexões de Gina Saraceni (2008) que, em Escribir hacia atrás. Herencia, lengua, memoria, entende a herança como uma "dívida que o herdeiro contrai com seus antecessores" e também "como um processo de leitura e interpretação de um legado". Quero dizer com isso que, nos poemas de Kamenszain, naqueles de El ghetto, mas também em vários poemas dos livros posteriores ou no ensaio "El ghetto de mi lengua" (2006), há um reconhecimento do legado paterno associado não unicamente, mas fundamentalmente, ao judaísmo, e trata-se de um legado que o sujeito lírico recebe, reconhece - transmite, inclusive -, mas não aceita por completo, uma vez que ele aparece sempre delineado em uma posição que poderíamos definir como de pertença reticente.

Por outro lado, e ainda em diálogo com Saraceni, acredito que, desde De este lado del Mediterráneo, no qual ela "reconstrói" uma linhagem vinculada aos avós, em El ghetto e em vários poemas dos livros posteriores, inclusive no último em que retorna com insistência ao tema dos campos de concentração em um cruzamento com os centros de detenção/ extermínio da última ditadura argentina, os poemas deixam transluzir o reconhecimento de uma dívida, ao mesmo tempo que é possível concebê-los como uma forma de interpretar esse legado, essa herança (de pagamento dessa dívida?).

Embora coincida com Saraceni em pensar a herança como dívida e como legado, tal como acabei de apontar, pergunto-me se essa herança de Kamenszain não participa de uma natureza dupla e contraditória: a de ser simultaneamente uma dívida e um dom, no sentido que Derrida atribui a esse conceito, enquanto algo diante do qual não há retribuição possível pela condição imposta pela morte. Também me pergunto isso pensando na afirmação de Derrida (1995, p. 101), quando declara que "O dom seria sempre o dom de uma escrita, de um relato, de um poema ou de um conto, o legado de um texto", de modo que, no processo de leitura e interpretação desse legado, ainda que se trate de um texto simbólico, poder-se-ia pensar que há um dom. E se avançarmos um pouco mais e pensarmos nos próprios poemas como textos que se inscrevem nesse processo e que estão dedicados ao pai, também poderíamos afirmar que aí volta a existir um dom, pelo menos o do tempo da escrita, pelo menos o do tempo do luto. 
Esse tempo dos livros que viriam, esse que, por volta do ano 1973, María Moreno imaginava que Tobías Kamenszain ia tomar da filha.

Agora, se pensássemos na recorrência da figura do pai, mas também na de diversas modulações da história familiar que se desdobram e se potencializam de uma obra a outra, bem como na recorrência do conceito de gueto, fundamental em vários dos seus livros de poemas e no ensaio "El ghetto de mi lengua" (KAMENSZAIN, 2006), ou na recorrência de um objeto como o anel de bodas dos pais, que adquire o caráter de um talismã através do qual se pode vislumbrar o passado, a origem familiar, imaginado como um toldo estendido no deserto, tal como sucede em Solos y solas (2005b), poderíamos postular que na poética dessa escritora o judaísmo aparece associado também a duas tensões de outra ordem - da ordem do procedimento. Por um lado, ao impulso para a narração, entendida como romance - como romance de sua (minha) vida -, impulso que se repete de um livro a outro e espreita como ameaça e desejo. Um tipo de discurso concebido sempre em sua relação com o "romance familiar", o que o subordinaria ao passado, baixaria o poema do "pódio metafórico", e não se esquivaria ao relato. ${ }^{7}$ Por outro lado, mas estreitamente ligado ao impulso narrativo, à tensão que percorre os poemas e os textos que os têm como objeto, a uma tensão entre o autobiográfico e o não autobiográfico, ou entre a primeira pessoa e a terceira, como um sinônimo de ficção. ${ }^{8}$

\footnotetext{
7 São muitas as vezes em que ao longo desses anos Kamenszain reflete acerca da relação entre sua poesia e o romance. Nesse sentido, transcrevo aqui um breve fragmento de uma entrevista que ela concede a Enrique Foffani, em 2010, e na qual é particularmente clara: "E a poesia parece surgir mais da estranheza diante do familiar, mais daquilo que falta do que daquilo que há. Parece-me que o romance é um gênero mais edípico, sempre remonta a historinha familiar, embora pareça falar de coisas objetivas, assuntos importantes do mundo. Em contrapartida, a poesia, que sempre parece falar de trivialidades pessoais, as desloca" (KAMENSZAIN, 2010, [s.p.]).

8 Essa ambiguidade se torna particularmente clara, explícita, em El libro de los divanes (KAMENSZAIN, 2014), onde além de revisar a relação entre sua poesia e as diversas análises como apontei no começo, o livro vai construindo uma interpretação fragmentária de seus poemas. Cada poema, uma sessão, assim como cada estrofe de "Kaddish", um dia de luto. El libro de los divanes lê o romance da sua vida e o romance da sua poesia em perspectiva, enquanto incorpora a voz de vários outros - os diversos analistas -, filtrados por aquilo que o sujeito em análise pode escutar. Nesse sentido são particularmente sugestivos alguns versos do poema de abertura. Evocando uma sessão na qual havia contado sobre a proximidade do aparecimento de seu primeiro livro na sua Poesía reunida, escreve: "Es un libro naíf, salvaje,/ tengo miedo de que me delate" (2012, p. 27). Seria preciso perguntar: O que é que delataria? Certo sentimentalismo? Certo regozijo e compromisso com o mito do judaísmo? Um excesso de marca autobiográfica? Por sua vez, evocando a figura que em La casa grande nomeou como "a sujeita”, escreve em "Narrarse a sí misma-versificar a la
} 
Com isso, quero dizer, ou perguntar-me, se "o judaico" na poética de Kamenszain vai mais além dos motivos e se traduz em uma pergunta pela narração, pela possibilidade do autobiográfico no poema e, inclusive, em uma pergunta acerca do lugar que cabe no poema àquilo que é íntimo. Pergunta, a segunda, que retorna com certa recorrência a 2003, a propósito da publicação de El ghetto, propiciada, em boa medida, pela dedicatória que abre o livro: "In memoriam Tobías Kamenszain. Em teu sobrenome instalo meu gueto" (KAMENSZAIN, 2003, p. 4). E se, nesses anos, a pergunta insiste, é com igual insistência que ela responde, de forma negativa, em cada uma das entrevistas que concede naquele momento. ${ }^{9}$

Apesar da negação do vínculo entre autobiografia e poema, que é possível ler no começo dos anos 2000 - quando, aliás, a poeta enfatiza o caráter reflexivo de sua escrita, uma vez que esta escrita se contaria, contaria seu próprio romance, uma negação que responde seguramente para livrar sua poesia de qualquer risco de essencialismo -, ao avançar na primeira e segunda décadas do século, Kamenszain publica uma série de livros - poemas e ensaios - nos quais vai rondando por diferentes finais e/ ou lutos: o da análise, em El libro de los divanes (2014); o luto pela morte dos amigos, daqueles que nascem em uma geração, em La novela de la poesía (KAMENSZAIN, 2012); o do fim de uma relação amorosa, em Solos y solas (2005b); o da morte da mãe, em El eco de mi madre (2010); o de formas da literatura e que atravessa vários deles; e dois livros de ensaios nos quais se pergunta acerca do modo como a poesia testemunha e narra, ou, ainda, se a poesia pode ou não dizer o íntimo, em La boca del testimonio (2007) e em Una intimidad inofensiva (2016). Consequentemente, a preocupação pelo essencialismo parece ter desaparecido para dar lugar, em contrapartida, a uma indagação em torno do modo como a poesia trabalha com a vida;

otra (El caso Molloy-Kamenszain)” (2016, p. 122): “[...] tive que aceitar, despojando-me de velhos pudores formalistas, que [...] aquela que chamei de 'a sujeita' não era outra senão, literalmente, eu mesma. 'Uma eu' que em El Ghetto (2003) defini como 'eu é outra', [...], mas que em El eco de mi madre já revela - desde o próprio título, onde o possessivo antecede a mãe - uma necessidade de afirmar-se para além dos avatares da enunciação, como essa sujeita 'que sou' ('não reprimir o sujeito que sou')" [tuve que aceptar, despojándome de viejos pudores formalistas, que [...] esa que llamé "la sujeta" no era otra que, literalmente yo misma. Una yo que en El Ghetto (2003) definí como “yo es otra”, [...], pero que en El eco de mi madre ya revela -desde el título mismo donde el posesivo antecede a la madre- una necesidad de afirmarse más allá de los avatares de la enunciación, como esa sujeta "que soy" ("no reprimir el sujeto que soy")].

9 Cf., entre outras, a entrevista concedida a Luis Chitarroni no jornal Página 12 (KAMENSZAIN, 2005a).

Remate de Males, Campinas-SP, v.39, n.2, pp. 684-702, jul./dez. 2019 - 689 
um questionamento indissociável da indagação em torno daquilo que distingue o poema da narrativa e que se radicaliza em seus últimos três livros: La novela de la poesia (2012), El libro de los divanes (2014) e Una intimidad inofensiva (2016). ${ }^{10}$ Esse deslizamento se faz de forma paralela ao que eu chamaria uma radicalização da aposta no caráter reflexivo de sua escrita que, entendo, está na origem do livro de 2012, partindo do título, o qual simultaneamente dá nome a esse novo livro e à sua poesia reunida.

A partir desse breve percurso que tracei, pretendo ler nessas obras, particularmente nos livros de poemas, algumas das cenas nas quais "o judaico" se inscreve explicitamente contra o fundo da tensão entre o romance e o poema, como discursos que retornam ou não ao familiar e, consequentemente, oscilam entre o autobiográfico e o não autobiográfico.

Comecemos pelo final: El libro de los divanes (o livro dos poemas) revisa, como eu disse, a relação entre aquilo que se conta na psicanálise e a escrita do poema, particularmente, penso, entre voltar ou não à vida - a própria vida - no poema, ou encontrar "outra linha”, outras vozes, as vozes de outros, algo que introduz em alguns lampejos que evocam sua participação na militância política no início da década de setenta." Uma indagação que se desdobra em poemas, nos quais claramente ela narra, explicita o desejo que a acompanha desde jovem de contar algo no poema sem que este deixe de ser poema. A esse respeito escreve nesse livro, cujas partes são chamadas de capítulos: “Los límites del poema-libro' llamé cuando era joven/ a la posibilidad de escribir un libro que todo entero// fuera de poemas/ y todo entero sin embargo/ contara algo" (KAMENSZAIN, 2014, p. 41).

$10 \mathrm{O}$ que acabo de indicar é particularmente evidente no já mencionado "Narrarse a sí mismo, poetizar al otro. Los casos Molloy-Kamenszain”, ensaio no qual ela começa narrando a perplexidade e o desassossego que ambas as escritoras sentiram diante da perda de uma interlocutora querida - a amiga em um caso; a mãe, no outro -, vítima do Alzheimer, uma experiência que as leva a escrever porque, como diz: "Esse era o desafio que [...] nos estava propondo, tanto a Sylvia como a mim: havia se tornado necessário registrar por escrito aquilo de que o passar do tempo ia retirando palavras" [Ese era el desafío que [...] nos estaba interpelando tanto a Sylvia como a mí: se había hecho necesario consignar por escrito aquello a lo que el paso del tiempo le iba quitando palabras] (KAMENSZAIN, 2016, p. 119).

11 Em um dos poemas, ela escreve: "En primera persona también me sumo/ quiero salvar con ellos algo de mi propia juventud/ un entusiasmo de grupo un nosotros naíf o salvaje/ que me permita creer que alguna vez me colé/ por los agujeros de las voces ajenas/ para encontrarme feliz y contenta/ con el eco de la mía" (KAMENSZAIN, 2014, p. 34).

Remate de Males, Campinas-SP, v.39, n.2, pp. 684-702, jul./dez. 2019 - 690 
A pergunta pareceria ser ou ter sido: "Contar sim; mas, contar o quê?". Nos versos seguintes aos que acabei de citar, Tamara Kamenszain (2014, p. 41) escreve:
Cuando volvimos de Gaspar Campos cansadas trans- piradas yo estaba escribiendo De este lado del Mediterráneo y nunca se me hubiera ocurrido consignar aquel presente.
Para parecer más grande me inventé un pasado un mito de origen la infancia judía como leyenda bíblica los Beatles descubiertos en Israel cuando escuchaba una radio árabe.
No Perón, no Evita, ni siquiera Montoneros, mi vida era la novela de mi vida y la realidad un invento de los otros.

Na memória de seus livros, ou na "história de seus livros", ou no relato do mito de origem da sua poesia, o judaísmo aparece evocado como uma fábula de nascimento, na qual lhe cabe a função não só de situá-la em uma genealogia - a familiar, mas também a do livro no deserto, o livro concebido como casa -, mas também a de evitar a inscrição do presente no poema, especificamente a inscrição da política naquele momento, ou, ao menos, não de forma direta. Inscrevê-la, em todo caso, por meio da recorrência a caminhos indiretos "para dar conta da realidade sem apelar aos realismos" (KAMENSZAIN, 2007, p. 11), ${ }^{12}$ porque, como aponta em $\mathrm{La}$ boca del testimonio, essa seria a única forma de não adulterar a verdade do testemunho (p. 11). ${ }^{13}$

Por um lado, o mito de origem judaica - concebido como o familiar e como aquilo que provê os termos para pensá-lo - é o polo que tensiona sua poesia para a narrativa e para o passado, ou o que a situa naquilo que $\mathrm{Amos} \mathrm{Oz}$ $(2015$, p. 109) chama "a nua ossada da transmissão" [la desnuda osamenta de la transmisión]; por outro lado, contudo, esse mito do qual não pode sair, ou não completamente, assim como não pode deixar de falar de si, situa sua poesia no limiar entre o romance e o poema, entre o diário íntimo e o poema. Embora esse vaivém entre o poema e o romance, entre narrar a intimidade como no diário

\footnotetext{
12 "[...] para dar cuenta de la realidad sin apelar a los realismos".

13 No entanto, recuperando uma reflexão de Barthes em A preparação do romance, poderíamos pensar a insistência no mito do judaísmo e no retorno reiterado do familiar nos poemas em outros termos. Cito: “a) 'Dizer aqueles que se ama'. Amar + escrever = fazer justiça àqueles que conhecemos e amamos, isto é, testemunhar por eles (no sentido religioso), isto é, imortalizá-los" (BARTHES, 2005, p. 28).
}

Remate de Males, Campinas-SP, v.39, n.2, pp. 684-702, jul./dez. 2019 - 691 
íntimo e deixar entrar "outra linha" esteja presente como desejo e incerteza em El ghetto (KAMENSZAIN, 2003), El eco de mi madre (2010) e La novela de la poesia (2012), entre outros, torna-se particularmente explícito em El libro de los divanes (2014, p. 33), no qual, em um dos poemas, anuncia: "voy a terminar cayendo en el diario íntimo y la poesía/ tendrá que versar sobre otros asuntos".

O "romance das origens", da sua vida e, junto com ela, da sua poesia, é um romance judaico, embora desde o início esse romance - essa fábula de origem - esteja rasgado por uma aura de certa transgressão e desejo de sair do universo judaico, porque com a mesma intensidade e recorrência há outro mito que o percorre: o que imagina que a realidade passa ou está do outro lado. Sair do romance, o da vida, permitiria que a realidade por fim começasse, que o outro, ou outros, ingressassem no poema. Algo que em El libro de los divanes (KAMENSZAIN, 2014, p. 36) a autora põe na boca da analista, na boca do outro/da outra, que lhe diz sobre si: "Usted puede viajar a Italia a ver si ahí encuentra el amor/ interpreta la analista buscando que acabe/ la novela de mi vida para que por fin empiece/ su realidad".

A que me refiro quando falo de certa transgressão ou de romper o mito do judaísmo, entendendo esse mito como uma espécie de arquivo que condensaria uma série de saberes fixos e definitivos? Falo de pequenos gestos, de gestos mínimos: escutar em Israel uma rádio árabe e ali conhecer a música dos Beatles; reconhecer um pertencimento e, ao mesmo tempo, se não negá-lo, inscrever no poema a distância ou o desconforto diante desse relato de origem; não se situar, nem situar o poema no âmbito de um pertencimento entendido como "o prazer do consabido" (KOHAN, 2006, p. 135). ${ }^{14}$ Há sim um mito de origem, no qual o ouro da linhagem está nas citações dos poemas de Celan que antecedem e dão a chave para cada uma das seções de El ghetto e cujos versos precedem "Alianza", o último poema de Solos y solas. ${ }^{15}$ Uma linhagem na qual também entram as diversas

14 A esse respeito, no começo de "El ghetto de mi lengua", onde reflete acerca das opções de sua poesia, Kamenszain (2006, p. 159) escreve: "Meu primeiro livro de poemas se intitula De este lado del Mediterráneo e parece que nesse título já existe, logo de início, uma fronteira marcada. 'Deste lado' supõe o outro. Esse parece ser o impulso primeiro que me levou a escrever poesia: a nostalgia pelo outro lado a partir deste. De início, esse título fundador marca um círculo de giz, um gueto, um limite que está aí esperando ser ultrapassado".

15 Ou seja, as citações de Celan dão o tom dos poemas articulados em torno do pai e do judaísmo, de modo que poderíamos dizer que é esse lugar em que deseja inscrevê-lo ou inscrever-se ou deslocar o judaísmo da ordem da cotidianidade e pensá-lo em um registro que o remeta a sua zona mais prestigiosa, aquela que privilegia a palavra e principalmente a palavra escrita.

Remate de Males, Campinas-SP, v.39, n.2, pp. 684-702, jul./dez. 2019 - 692 
citações e referências a Pizarnik, a quem lê sempre a partir de uma torsão judaica, ${ }^{16}$ ou as alusões a figuras como Freud e Spinoza, ou, ainda, à evocação que associa livro e deserto, cujo cruzamento está no centro do mito de fundação do povo judeu como tal. Mas na mesma medida, o presente do judaísmo se inscreve sistematicamente como desconforto, e a pergunta do sujeito lírico parece ser sobre o que fazer com esse lugar comum do judaísmo, entendido como clichê que se rejeita, mas do qual também se participa ou, pelo menos, diante do qual não se é totalmente alheio. Trata-se de um desconforto explicitado, entre outros versos, em: "Me pesa el muro que te cargo" (KAMENSZAIN, 2003, p. 25), do poema "Bar Mitzvá", de El ghetto, no qual a transição do filho da infância para a vida adulta judaica é colocada em cena, em uma alternância entre espaços e frases icônicas do judaísmo - o que poderíamos nomear como lugares da memória dentro do judaísmo - e o exterior da cidade, que também se conta como transição, mas, agora, pelas ruas de uma zona de Palermo até chegar a um salão de festas situado na esquina de Güemes e Scalabrini Ortiz. ${ }^{17}$

$\mathrm{O}$ verso que citei considero particularmente significativo, porque, na primeira pessoa que o abre, o sujeito lírico se responsabiliza pela transmissão ao mesmo tempo que esse mesmo gesto perturba. Se um bar mitzvá, como muitos outros ritos similares, é uma cerimônia de passagem, de sair de um estado para ingressar em outro, isto é, conota uma ideia de movimento (de salto, inclusive) - nesse caso, o de sair do encantamento da infância para dar passagem às obrigações e direitos da vida adulta, essencialmente poder ler a Torá na sinagoga -, o poema consegue transformar os verbos de movimento que vão narrando o trajeto até o salão de festas e, depois, a própria festa em verbos que falam de um trânsito muito pesado, como se atravessassem uma matéria viscosa. Lemos: "se atrasa intermitente", "empujo con todos", "un tránsito pesado" (KAMENSZAIN, 2003, p. 35). O eu lírico somente parece ter um descanso quando, já dentro do salão, o poema joga com o significante ronda como substantivo e ronda como verbo. Escreve: "practicamos en ronda tus

16 Cf. "Testimoniar sin lengua (el caso Alejandra Pizarnik)", o capítulo II de La boca del testimonio (KAMENSZAIN, 2016, pp. 63-115), ou as remissões a essa poeta, ao seu nome especificamente, em El eco de mi madre.

17 Cito a primeira estrofe do poema: "El año que viene en Jerusalem./ ¿Y mientras tanto?/ Esquina de Güemes / y Scalabrini Ortiz./ Se atrasa intermitente/ la locación del semáforo/ y un permiso de luz/ enciende tu ceremonia./ Me pesa el muro que te cargo/ con la vista puesta en la espalda/ el horizonte nos señala otra patria" (KAMENSZAIN, 2003, p. 25).

Remate de Males, Campinas-SP, v.39, n.2, pp. 684-702, jul./dez. 2019 - 693 
trece/ y si me ronda un buen partido/ lo dejo ir: demasiado familiar/ para tanta lejanía" (KAMENSZAIN, 2003, p. 25). A figura do trânsito, da passagem, é substituída pela da ronda - o círculo -, da qual, no entanto, pode desprender-se completamente.

Enquanto em "Bart Mitzvá” o sujeito lírico se encarrega da pesada herança que transmite ao filho varão, "La alianza”, o último poema/seção de Solos y solas (KAMENSZAIN, 2005b), abre-se com os seguintes versos: "Me quedé con la alianza de mi padre/ en terapia intensiva se la sacó la enfermera/ era un edema el dedo de la diálisis/ la retuvieron con esfuerzo las falanges en/ [crecimiento de mi hijo/ hasta que resbaló y yo pude mirar a través de ese círculo privilegiado" (p. 45).

São essa cena e esse objeto concreto e simbólico os que propiciam o retorno do pai a um livro cujo primeiro plano está ocupado pelos encontros e desencontros com outros homens, aqueles solitários conotados como "solitarios baratos", ou, como o próprio sujeito lírico, descritos como "parias de casamentera", homens que ao longo do livro parecem estabelecer um contraponto - desejável e temido - à aliança do sujeito lírico com o pai, já que como diz, nesse poema que recupera e sintetiza aqueles das seções anteriores: "de qué me avergüenzo entonces/ si lo que me pesa desde la cuna todavía/ para bien o para mal no es otra cosa/ que la alianza con mi padre" (KAMENSZAIN, 2005b, p. 47).

Mas voltemos à abertura do poema, àquilo que ele evoca nos primeiros versos. Na margem, no limiar entre a vida e a morte, os cinco versos iniciais esboçam uma cena de transmissão entre gerações na qual, diferentemente do que "sucede" em "Bar Mitzvá", o sujeito lírico não impõe ao filho o muro da tradição; em vez disso, encarrega-se da aliança, desse objeto que o pai já não pode reter e que se escapa do filho adolescente. Uma aliança que remete ao casamento de seus pais, daqueles que se casaram para tê-la ("son mis padres se casaron para tenerme" (KAMENSZAIN, 2005b, p. 46), uma aliança que remete ao vínculo entre o sujeito lírico e o pai e, que, em boa medida, remete também ao judaísmo, se não no sentido da aliança entre Deus e os homens, embora esta esteja suposta, pelo menos ao laço que o poema traduz, com fastidiosa resignação, como "a monogamia dos meus”; isso que se aprende e se herda desde pequena. Mas, sobretudo, no presente do poema, a aliança é um dispositivo privilegiado para poder olhar, através do espaço vazio do círculo, a história familiar, beliscar na história familiar, beliscar a história familiar. "[Y] yo me hago niña picoteo de esa alianza" (p. 49) - escreve. 
Diferentemente de "Kaddish" - um poema que se constrói como uma ladainha sonolenta e que em cada estrofe, iniciada pela pergunta "¿Qué es un padre?", coloca em cena o presente da reza, uma reza na boca de outros, outros homens, um "círculo masculino" do qual somente quer se libertar para poder ser órfã -, "La alianza" volta à imagem do círculo, não mais à do "círculo masculino" da reza, e sim ao "círculo privilegiado" do anel, através do qual tenta revisitar a história familiar, apropriar-se dela, cujo devir o poema relata no cruzamento entre várias séries: a de lugares de memória do judaísmo (o deserto), a citação do tango ("el camino de los sueños", "si adivino el parpadeo"), a língua da literatura ("un golpe de tarot"), o discurso amoroso (KAMENSZAIN, 2005, pp. 48, 50 e 49, respectivamente). Através do ouro do anel, daquilo que esse ouro deixa ver, o poema situa a origem da genealogia familiar no deserto, momento em que o povo judeu se constitui como tal. “ ¿[Q]ué veo cuando veo algo en el nombre del oro?” (p. 45), pergunta-se, e o resto da estrofe desdobra uma cena na qual o momento fundacional do judaísmo se sobrepõe ao momento inicial da história familiar, no qual o toldo se confunde com o pálio nupcial. Cito a estrofe completa:

\footnotetext{
¿Qué veo cuando veo algo en el nombre del oro? una esperanza desplegada en otro tiempo toldo de dos que se apropiaron del desierto dibujaron un techo nuevo sobre nada lo que tapa la cabeza de los que se casan es una telita apenas si se hincha parece sábana desvelada sobre cuatro palos ellos miraron hacia arriba y quedó claro que desde esa noche dormirían abajo (KAMENSZAIN, 2005b, p. 46).
}

Avançando no poema, a imagem do toldo - toldo do deserto e telhado do casamento - converte-se em "telhadinho da literatura", cuja lei é outra, é própria, e não a lei do casamento, nem a lei recebida no deserto, de modo que se pode propiciar o inesperado, um ritmo novo, e já não o da história familiar. Lemos: "la literatura es otro techito armado en el [desierto/ se conmemora como enlace judío/ cuando la palabra cobija en su propia ley/ un ritmo nuevo una melodía inesperada" (KAMENSZAIN, 2005b, p. 48).

Diria então que, enquanto em El ghetto o sujeito lírico não se reconhece na reza dos outros, ao mesmo tempo que se inscreve como filha de "Tuvia ben Biniamin" para continuar a busca, para continuar a pergunta, essa que não tem resposta - “QQué es un padre?” -, em “La 
alianza”, esse sujeito que se posiciona como uma herdeira, a do anel, claro, e também a da história familiar confundida - ou quase confundida - com a história judaica, coloca o relato familiar em perspectiva e aposta em um ritmo novo, em uma história diferente, em "una infancia nueva”, que não se confunda ou não se limite à do imaginário judeu.

Se, como vimos, os livros vão construindo uma série de ligações entre si, tal como afirma acertadamente Enrique Foffani ${ }^{18}$ e criando desse modo um relato familiar permeado pelos vínculos de seus membros com o judaísmo - valores, práticas, expectativas -, algo que se conta desde os títulos das obras, cabe afirmar que aos poemas retornam também conceitos que podemos chamar matriciais, como o termo gueto que, conforme vimos, insiste nas primeiras obras, dá título ao livro de 2003, articula o ensaio "El ghetto de mi lengua" e reaparece em El eco de mi madre (2010), como significante em um poema, mas também como um conceito que ajuda a pensar a enfermidade que espreita essa mulher e que, à maneira de uma "maldita circunstância", traça um círculo do qual ninguém pode sair. Refiro-me especificamente à materialidade do termo gueto, mas também às situações de confinamento e saída que se podem seguir em seus textos e que a evocam e a pressupõem.

Em El libro de los divanes (2014), no qual traça um jogo entre a respiração asmática e a respiração do poema como o íntimo, a voz dos analistas como uma das entradas da voz dos outros e o familiar como confinamento, o termo gueto reaparece como aquilo que conota o familiar que sufoca, sufoca na asma e sufoca nas metáforas burguesas que nomeiam a enfermidade como cansaço. "Mi segundo analista me señaló el miedo a viajar/ despegarte del círculo familiar dijo/ como si un océano tuviera que por fin separar/ lo que seguía fijo en la habitación de al lado./ Un círculo o un ghetto" (KAMENSZAIN, 2014, p. 29).

Quase no final do mesmo poema, e embora já não se mencione, a associação entre gueto e confinamento reaparece com uma dupla conotação. Por um lado, como sinônimo do confinamento materno com o irmão enfermo e como antecipação do segundo confinamento, agora simbólico, dessa mulher afligida pelo Alzheimer; mas por outro, também engloba o sujeito lírico, que está separado no quarto ao lado: "yo ya había nacido separada/ en el cuarto de al lado de mi madre/ que encerró su

18 No prólogo a Poesía reunida, ele anota: "Do primeiro ao último, se estabelecem entre os livros de poemas elos compositivos” (FOFFANI, 2012, p. 9). 
amor contra el mío/ esperando la cura de un bebé terminal/ que no era yo" (KAMENSZAIN, 2014, p. 30). ${ }^{19}$

E, se essa separação em El eco de mi madre (2010) aparecia como a impossibilidade de narrar ("y algo me va quedando claro: no puedo narrar/ nunca pude me solté rápido de la mano de ella” - 2010, p. 49), ${ }^{20} \mathrm{a}$ partir desse livro parece ficar claro que a separação, o ter se soltado da mão da mãe, é o que confere a possibilidade de escrever poesia a partir da sua própria respiração. Justamente porque pode desprender-se, porque está no quarto ao lado, separada.

Agora, em um sentido diferente, se de forma geral a entrada da voz dos outros aparece nos poemas como uma espécie de fuga do gueto, ou da própria vida ou do judaísmo, em um dos poemas de El libro de los divanes (KAMENSZAIN, 2014), a voz desses outros aparece como uma ameaça que a obriga ao recolhimento, a refugiar-se no gueto de sua própria intimidade. Lemos:

No sé pero todavía hoy cuando un taxista dice

algo sobre los judíos me callo

no vaya a ser que por el espejo retrovisor descubra

que yo también estoy al borde de esa fosa.

Por eso no opino por eso me escondo

detrás de la primera persona (KAMENSZAIN, 2014, p. 49).

Um poema que é singular porque expõe um sentimento de extrema vulnerabilidade em relação à condição judaica, que não se deixa ler/ver em outros poemas, nem desse livro nem de livros anteriores. Poder-se-ia pensar que pontualmente esse poema permite surgir outra linha vinculada ao judaísmo, a linha do medo e do segredo, que a escritora em geral relaciona com os pais e na qual se aprofundou em "Testimoniar sin lengua (El caso Alejandra Pizarnik)” de La boca del testimonio (KAMENSZAIN, 2007, pp. 63-115).

19 A associação entre a enfermidade e a morte do irmão pequeno e o gueto como aquilo que metaforiza o isolamento daquela "burguesía oscura envuelta en gobelino", confinada nos limites da casa, pode-se ler também nestes versos de "El libro cortado", terceira seção/ poema de El eco de mi madre: "la muerte casera en mi casa erigió el eco de un tabú/ éramos una burguesía oscura envuelta en gobelino/ tapábamos con cortinas nuevas como diciendo NO /PASARÁN/ de la ventana para afuera un mundo impronunciable/ nos acosaba y yo adentro haciendo en ghetto los deberes" (KAMENSZAIN, 2010, p. 48).

20 Desenvolvi esse aspecto de El eco de mi madre em "La que oyó su nacimiento: El eco de mi madre de Tamara Kamenszain” (KANZEPOLSKY, 2012, pp. 37-44).

Remate de Males, Campinas-SP, v.39, n.2, pp. 684-702, jul./dez. 2019 - 697 
Se em "La Alianza” Kamenszain situa e sobrepõe a origem da história familiar à construção de um toldo no deserto, um toldo que é metáfora do livro em sentido literal, mas que também alude ao livro da vida outra imagem que a acompanha nas sucessivas obras -, a partir do que poderíamos pensar quea história familiar está concebida como um trânsito, como um nomadismo, trânsito primeiro a partir do deserto, mas depois da Europa para a Argentina, ou inclusive trânsito da escrita de direita para esquerda em hebraico e de esquerda para direita em castelhano; quando os poemas voltam para a cotidianidade da vida familiar, a imagem que se impõe não é a do trânsito, mas sim a do gueto, aquele confinamento ou aquele segredo que sufoca e do qual o sujeito lírico tenta reiteradamente sair, desobstruir as portas dessa "burguesía oscura envuelta en gobelino", onde a menina faz seus deveres, ou sair do cemitério judeu para o campo aberto da Grande Buenos Aires, como em "Árbol de la vida", o poema no qual começa a fechar o luto pelo pai, para deixar entrar o verde que avança sobre todos em uma tarde de domingo. ${ }^{21}$

As saídas ou os movimentos que apontam para sair do gueto são múltiplos, mas penso que se dão principalmente a partir do movimento de abrir o poema à voz dos outros, ${ }^{22}$ isto é, escutar a palavra dos outros

$21 \mathrm{O}$ gueto como aquilo que metaforiza o isolamento dessa "burguesía oscura envuelta en gobelino", confinada nos limites da casa, pode-se ler também nestes versos de "El libro cortado", a terceira seção/poema de El eco de mi madre: "la muerte casera en mi casa erigió el eco de un tabú/ éramos una burguesía oscura envuelta en gobelino/ tapábamos con cortinas nuevas como diciendo NO /PASARÁN/ de la ventana para afuera un mundo impronunciable/ nos acosaba y yo adentro haciendo en ghetto los deberes" (KAMENSZAIN, 2010, p. 48). Por sua vez, os versos finais de "Árbol de la vida" dizem: "Me fui del cementerio/ yo tampoco merezco otro domingo en tinieblas./ Mi duelo, lo que estoy viendo/ será de aquí en más este verdor que te dedico./ Hoy florecen en las copas de los árboles todas mis/ raíces" (2003, p. 44).

22 A esse respeito, vale a pena confrontar a excelente resenha de Adriana Astutti (2013) a La novela de la poesía, publicada na revista Caracol do Programa de Pós-Graduação em Língua Espanhola e Literaturas Espanholas e Hispano-Americanas da FFLCH-USP. Reproduzo dois fragmentos: "Mas se Kamenszain conta a vida sem identificação nem pateticismo é, entre outras coisas, porque Kamenszain conta em diálogo com outras vozes. Se tivéssemos que resumir sua trajetória em uma frase, poderíamos dizer que a voz que Tamara Kamenszain construiu ao longo de seus livros é uma das matrizes de diálogo da poesia argentina atual. Kamenszain abre com seus poemas e ensaios um espaço de encontro no qual ingressam as vozes, da rua, das letras de tango, e as vozes de outros escritores" (ASTUTTI, 2013, p. 193). E mais abaixo: "A citação, então, em Kamenszain, consiste não apenas em dar lugar à frase do outro e convocá-lo como par, como escritor, como respaldo, mas também em um convite ao outro e na evocação de uma forma da intimidade nesses diálogos" (p. 193).

Remate de Males, Campinas-SP, v.39, n.2, pp. 684-702, jul./dez. 2019 - 698 
no poema, como apontei, fazer presente a boca dos outros no poema e, também, recorrer a imagens e fragmentos da literatura argentina ou do acervo da língua e cultura argentinas, esse bem comum, para dizer o judaísmo ou para dizer o íntimo. Penso, por exemplo, em um verso de "Kaddish", que é uma espécie de citação parafraseada do Martín Fierro, ou em um verso de "Judíos", que recorre a uma copla para defini-los, para dizê-los, ou ao nome de um grupo de rock argentino para falar da própria família. ${ }^{23}$

O gueto, um lugar e/ou um conceito tão inextricavelmente ligado ao judaísmo, apresenta-se, então, na poética de Kamenszain como um limite que sistematicamente se deve transpor. Isto é, trata-se de um "espaço" que em sua poesia adquire um caráter paradoxal, porque, para além do viés de familiaridade que o acompanha, literalmente em sua realidade histórica ou simbolicamente na história familiar, é um âmbito que o sujeito lírico não reconhece como próprio ou, pelo menos, do qual não se apropria no poema. Só está aí para poder apostar na ruptura disso que em um dos primeiros ensaios chamou de "o círculo de giz". Quero dizer que o gueto, entendido sobretudo como o comunitário e o familiar, não adquire nessa poesia o caráter de uma posição íntima, no sentido em que François Jullien (2016, p. 24) define tal categoria, quando destaca que

O íntimo designa [...] duas coisas que mantém associadas: o retiro e o compartilhar. $\mathrm{Ou}$, melhor dizendo, devido inclusive à possibilidade do retiro, surge a solicitação de compartilhar. Não apenas, evidentemente, porque quanto mais íntimo é aquilo que está em jogo, mais profundo é o que se compartilha. Mas também, sobretudo, porque somente o que é íntimo se quer oferecer e pode fazê-lo.

E é dessa perspectiva que me perguntava no começo do texto se o judaísmo em Kamenszain transcendia os motivos e podia associar-se a

23 Em “Día del perdón”, escreve: “Qué pedimos?/ No que él vuelva./ Sí que nos deje tranquilas/ planchadas en su recuerdo ansiolítico/ demoradas contra nuestro destino/ de padre y marido ido" (KAMENSZAIN, 2003, p. 37, grifo meu). Em “Judíos", também de El ghetto: "Pueblito que baja y se pierde/ ni raza ni nación ni religión" (p. 50). E, por último, em "Antepasados" escreve: "dueños de un desierto que avanza/ bisabuelos de la nada” (p. 21), em clara alusão ao grupo de rock Los Abuelos de la Nada. Como aponta Astutti na nota anterior, o diálogo com outras vozes é uma constante da poesia de Kamenszain. Tomei apenas três exemplos concretos, mas o mesmo tipo de operação pode ser lido em relação a versos de Lezama, Vallejo, Pizarnik, Perlongher, Mallarmé etc. Ou com uma série de tangos de Gardel e Le Pera, para mencionar algumas das vozes que a escritora incorpora aos poemas.

Remate de Males, Campinas-SP, v.39, n.2, pp. 684-702, jul./dez. 2019 - 699 
uma pergunta pelo autobiográfico e pela possibilidade do íntimo no poema. A resposta não é simples: a princípio poderia afirmar que o íntimo no poema não é o romance, o romance judaico, mas sim que o íntimo é a respiração que está associada ao corte do verso, porque, como escreve no segundo poema de El libro de los divanes:

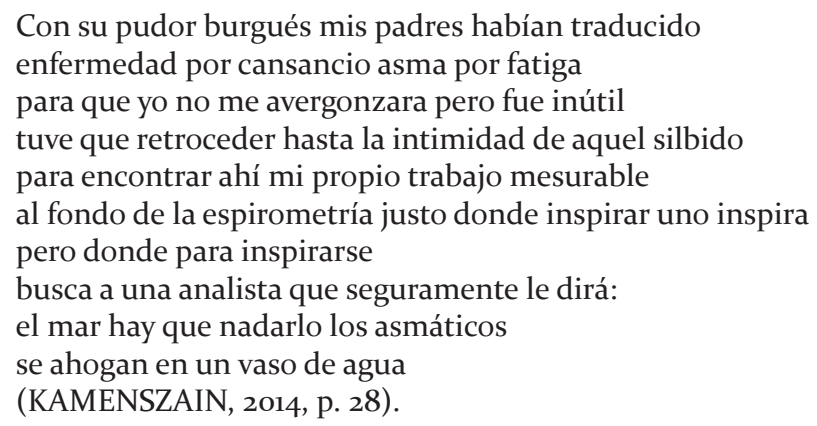

De forma que, se na poesia dela se pode falar de intimidade, esta passa exclusivamente por aquilo que de recôndito pressupõe o termo, e não pelo que se entende como espaço que se abre entre duas pessoas (JULLIEN, 2016). No entanto, quando nos detemos em El eco de mi madre (KAMENSZAIN, 2010), um livro que aparentemente se faz por fora das margens do judaísmo e da história, este desponta com uma torsão diferente, quase como uma epifania que se deixa escutar como língua íntima.

Atravessado por uma série de lutos e perdas (a da mãe como testemunha que fica sem língua para narrá-la, a da impossibilidade do romance que os poemas situam no momento da morte do irmão durante a infância, entre outros), El eco de mi madre está construído sobre o eco da repetição e o balbuciar que marca a enfermidade dessa mulher - o Alzheimer -, e se dilata em versos como "quiero guiarla pero se le suelta la lengua" ou "y me pierde a mí en otro idioma" (KAMENSZAIN, 2010, p. 18), para dar apenas dois exemplos. Ou inclusive em um poema em que dialoga com Desarticulaciones de Sylvia Molloy (2010), onde também se relata a relação com alguém íntimo que sofre de Alzheimer: "Correctas educadas casi pomposas/ estas rehenes del Alzheimer/ ponen a congelar la lengua materna/ mientras nos despiden de su mundo sin palabras" (KAMENSZAIN, 2010, p. 27). Mas em seguida, no verso seguinte, o iídiche, enquanto língua da infância da mãe, instaura por um momento a possibilidade - talvez ilusória - de alguma comunicação: "Sin embargo" 
- diz o poema - "si te canto tu canción infantil/ la neurona del idisch se posa dulce sobre tus labios/y todo lo que nunca entendí en ese idioma/ lo repito con vos viejita, y me queda claro" (p. 27).

Há aí na fugacidade desse momento, na fugacidade do sorriso e na compreensão súbita de algo que ela não sabia que sabia, como também no uso do vocativo no qual a mãe volta a ser sujeito, um ingresso inesperado do judaico como uma língua íntima, no sentido de algo recôndito e inesperadamente compartilhado. Não se trata agora de um romance que fala das origens familiares e culturais, mas sim de um ritmo acoplado ao murmúrio de uma canção infantil.

\section{$\overline{\text { REFERÊNCIAS }}$}

ASTUTTI, Adriana. “Óyeme, mi oíme”: Tamara Kamenszain. La novela de la poesía. Poesía reunida. Caracol, n. 5, 2013. Disponível em: <https://www.revistas.usp.br/caracol/>. Acesso em: 17 jun. 2019.

BARTHES, Roland. A preparação do romance. São Paulo: Martins Fontes, 2005.

BAUAB, Adriana. Los tiempos del duelo. Rosario: Homo Sapiens, 2001.

DERRIDA, Jacques. Dar (el) tiempo. I. La moneda falsa. Buenos Aires: Paidós, 1995.

FOFFANI, Enrique. Tamara Kamenszain: la poesía como novela luminosa. In: KAMENSZAIN, Tamara. La novela de la poesía. Buenos Aires: Adriana Hidalgo Editora, 2012, pp. 5-47.

JULLIEN, François. Lo íntimo. Lejos del ruidoso amor. Buenos Aires: El cuenco de plata, 2016.

KAMENSZAIN, Tamara. El ghetto. Buenos Aires: Sudamericana, 2003.

KAMENSZAIN, Tamara. El motivo es el poema. [Entrevista a Luis Chitarroni]. Página 12 [on-line], 2005a. Disponível em: <https://www.pagina12.com.ar/diario/ suplementos/libros/10-1803-2005-10-30.html>. Acesso em: 17 jun. 2019.

KAMENSZAIN, Tamara. Solos y solas. Buenos Aires: Lumen, 2005b.

KAMENSZAIN, Tamara. El ghetto de mi lengua. In: MOLLOY, Sylvia; SISKIND, Mariano (Eds.). Poéticas de la distancia. Adentro y afuera de la literatura argentina. Buenos Aires: Norma, 2006, pp. 157-169.

KAMENSZAIN, Tamara. La boca del testimonio. Lo que dice la poesía. Buenos Aires: Norma, 2007. 
KAMENSZAIN, Tamara. La extraña familia. [Entrevista concedida a Enrique Foffani]. Página 12 [on-line], 2010. Disponível em: <https://www.pagina12.com.ar/diario/ suplementos/libros/10-4034-2010-10-24.html>. Acesso em: 17 jun. 2019.

KAMENSZAIN, Tamara. La novela de la poesía. Buenos Aires: Adriana Hidalgo Editora, 2012.

KAMENSZAIN, Tamara. Una intimidad inofensiva. Los que escriben con lo que hay. Buenos Aires: Eterna Cadencia, 2016.

KANZEPOLSKY, Adriana. Aquí llegamos, aquí no veníamos. Hispamérica, n. 15, 2010, pp. 75-87.

KANZEPOLSKY, Adriana. Revista do Centro de Estudos Portugueses (UFMG), n. 34, 2014. Disponivel em: <http://www.periodicos.letras.ufmg.br/index.php/cesp/article/ view/6931/5927>.

KELL, Maria Rita. Melancolia e Criação. In: FREUD, Sigmund. Luto e melancolia. São Paulo: Cosac Naify, 2014, pp. 8-31.

KOHAN, Martín. La emigración en ciernes. In: MOLLOY, Sylvia; SISKIND, Mariano (eds.). Poéticas de la distancia. Adentro y afuera de la literatura argentina. Buenos Aires: Norma, 2006, pp. 129-140.

MORENO, María. La musa freudiana. In: KAMENSZAIN, Tamara. El libro de los divanes. Buenos Aires: Adriana Hidalgo Editora, 2014, pp. 7-21. (Colección Fuera de Serie)

OZ, Amos; OZ-SALZBERGER, Fania. Los judíos y las palabras. Madrid: Siruela, 2013.

SARACENI, Gina. Escribir hacia atrás. Herencia, lengua, memoria. Rosario: Beatriz Viterbo Editora, 2008.

TERÁN, Oscar. Historia, memoria [apresentação]. Jornada Académica organizada por el Doctorado en Ciencias Sociales y Humanidades, Universidad Nacional de Quilmes, 2003. (mimeo)

Recebido: 19/06/2019

Aceito: 12/09/2019

Publicado: 26/11/2019

Remate de Males, Campinas-SP, v.39, n.2, pp. 684-702, jul./dez. 2019 - 702 